from future attacks. However, future attacks are more probable than in cases where repeated attacks of a milder type have led to cicatrisation or atrophy of the organ?" Page 517: "Mortality after operation for local abscess, 13.4 per cent." Of cases which recovered and had been followed up there were recurrences in 39.9 per cent., and 70 per cent. of these recurrences were accompanied by fresh suppuration. In 18 cases a subsequent interval operation was performed, and in all the appendix was found capable of giving rise to fresh attacks. All the cases recovered.

Let me now say a few words about the cases I have tabulated, and in so doing I will take the headings.

1. Age.-You will note that all the cases are of young people. This is accounted for by the fact that this disease is commoner in the young, and that when an abscess has been opened and drained in an elderly person $I$ have not advised a second interval operation, but have told the patient to await a second attack and then have an immediate operation. In young people, however, I have always advocated a subsequent interval operation, as they are more likely to be in inaccessible places when another attack occurs-Canada, Switzerland, \&c.

2. History of attacks.-Here is one of the strong reasons in my opinion for an interval operation as soon as convenient. Out of 17 cases there were multiple attacks in Nos. $6,8,9$, 16 , and, if I may mention another case, A B (9), who had an abscess opened and drained in 1902; in 1904, peritonitis and two operations, appendix not removed. In $1911 \mathrm{I}$ heard from the mother that he had had another severe attack in France, and asking if the appendix had been removed and whether I advised its being taken away if it had not. In these cases you will see that sometimes several years elapsed between abscess formation and a fresh attack. (Nos. 6 and 8 , and $\mathrm{A} \mathrm{B}$.)

3. Nature of primary operation. - In all cases drainage only, as now advised by the majority of surgeons. Most of the cases did not ceme into the surgeon's hands till more than a week after onset of symptoms. Under these circumstances the abscess cavity is usually well defined and the appendix almost impossible to find and remove. When one is able to get at the cases before 48 hours there is rarely any difficulty in doing this, and in the great majority of cases now sent into hospital we see them before the third day of disease (often much earlier), and hence the difference in the nature of the operation.

4. Final operation.-Not difficult as a rule. Route : Rectus in all cases on account of the possible difficulties from adhesions ; but in the majority of eases these were conspicuous by their smallness. They were marked in Nos. 6, 8, and 16, when I think any other incision would have made the removal extremely difficult, but I do not propose discussing these incisions here. One most remarkable thing to me is the absence of many adhesions in such cases as Nos. 3, 9, and 12. Difficult cases are usually those with numerous subacute attacks.

5. Condition of appendix.-(a) Found and removed in all cases. (b) No obliteration of lumen. (a) Fæcal concretions in two cases (Nos. 11 and 16 and ? No. 9). (d) No destruction of appendix as a whole. (e) Gross anatomical and pathological changes, such as kinks, scarring, and strictures.

6. Results. - Recovery in all cases. In fact, the present mortality of appendectomy in the "interval" stage is, if anything, below 2 per cent., as already stated.

7. Ventral hernice.-These are in my experience frequent after the drainage of abscess through the abdominal wallA B, Nos. 6, 9, 10, 12, and 15. So that one is able to remodel the abdominal wall as well as remove a diseased appendix.

Therefore the general conclusions I am able to state are :-

1. The appendix was never destroyed but was damaged.

2. There was decided liability to fresh attacks with such diseased organs in the belly. 3 . In the present keen struggle for existence it is wiser to remove such a menace to life. 4. The danger of a second operation is not great, and berniæ may at the same time be cured. So far mortality nul.

In conclusion, I would like to state that these 17 cases are in no way picked, but are taken over a number of years out of 250 cases, just as they came under my care, and I am deeply disappointed that I am unable to show you the whole series of the appendices, but that is not my fault but misfortune.

Oxford.

\section{A CASE OF TUBERCULOSIS WITH SPECIAL INVOLVEMENT OF THE HEART.}

BY PHILIP BAHR, M.A., M.B., B.C., D.T.M. \& H. САMB.; AND

GEORGE C. LOW, M.A. ST. AND., M.D. EdIn., C.M. (From the London Sohool of Tropioal Medioine.)

AFFECTIONS of the heart wall are comparatively rare in tuberculosis ; therefore we offer no excuse for publishing the following interesting details of such a case.

The patient, a Fijian female, about 25 years of age, was admitted to the Colonial Hospital, Suva, Fiji, under the care of Dr. G. W. A. Lynch, chief medical officer, Fiji, on Nov. 28th, 1910, suffering from hæmoptysis. On admission the following notes were made. Temperature irregular, rising from normal to $99^{\circ}$ or $100^{\circ} \mathrm{F}$. at night, with a morning fall frequently as low as $96^{\circ}$. The patient was very weak, emaciated, and very anæmic, ascites also being present. An examination of the respiratory system gave well-marked signs of tuberculosis at both apices, similar physical signs being found lower in the lungs as well, while at the bases behind a considerable quantity of fluid was present. As regards the circulatory system, the heart was greatly enlarged, the apex beat lying in the fifth space almost at the anterior axillary line, while the borders in the other directions also lay much beyond their normal limits. On auscultation the cardiac sounds were very indistinct, but a systolic murmur could be detected at the base of the organ.

FIG. 1.

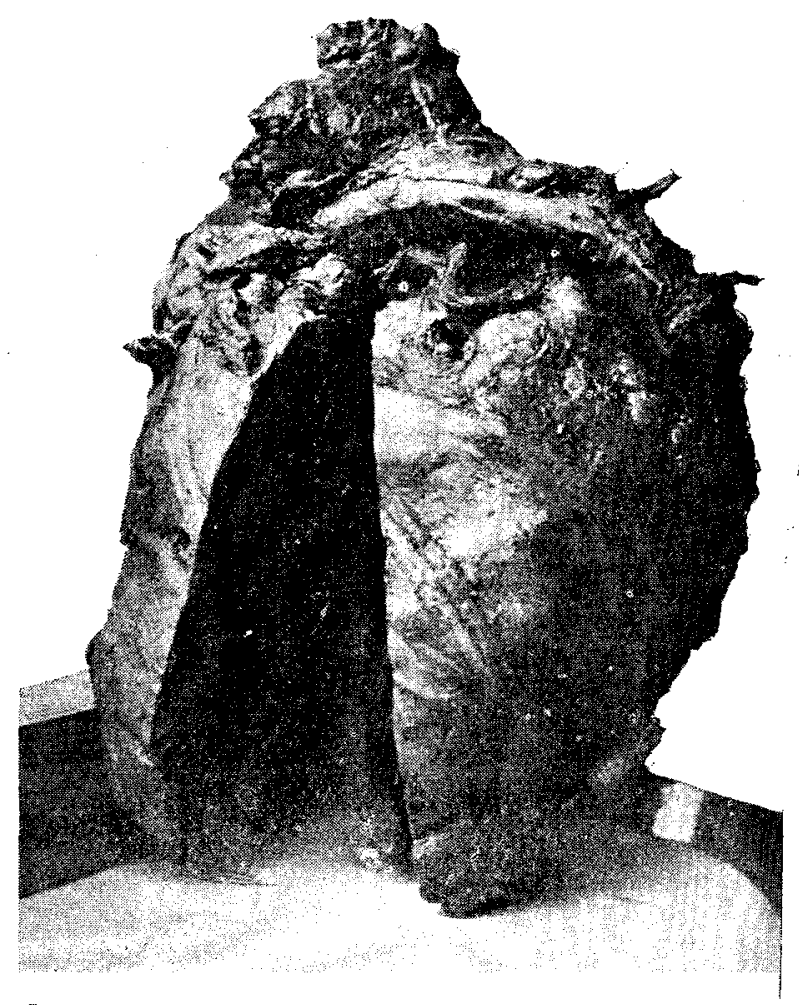

Heart showing the outside appearances specially. The nodular tubercular masses are well seen. N, Nodules or tubercular masses.

This murmur did not anpear to be conducted. The abdomen was prominent, fluid evidently being present. Of the abdominal viscera the spleen appeared to be normal, but the liver was enlarged, feeling hard to the touch, though not nodular, while the lower edge was easily palpable. The urine was acid, of specific gravity 1020 , albumin being present in considerable quantity, but no blood or sugar. The patient rapidly went downhill and died from heart failure on Dec. 12th.

At the necropsy performed by Dr. F. N. Smartt next day the following pathological lesions were found. The pericardial sac contained an excess of straw-coloured fluid. There was no pericarditis, the membrane not being thickened, but it was adherent to the surface of the heart at the base. 
No tubercles were detected on it. The beart was very large, weighing $37 \mathrm{oz}$. on removal. It presented a most unusual appearance, the walls both of the auricles and ventricles being studded with nodular masses of the shape and size of small marbles. The organ was not opened at the time of the necropsy, but was preserved and brought to England entire, Both pleural sacs contained a great excess of clear straw-coloured fluid. On the right side many adhesions bound the lung to the chest wall, while numerous miliary tubercles could be seen dotted over the pleural membrane on both sides. On section fairly advanced tubercular lesions, from miliary tubercles up to caseating masses of the size of hazel nuts, were found scattered through both lungs. The apices were both involved. The bases of the organs behind showed considerable oedema.

Of the other viscera, the liver was hard, bile-stained, and typically nutmeg; it weighed $56 \mathrm{oz}$. The spleen was

FIG. 2.

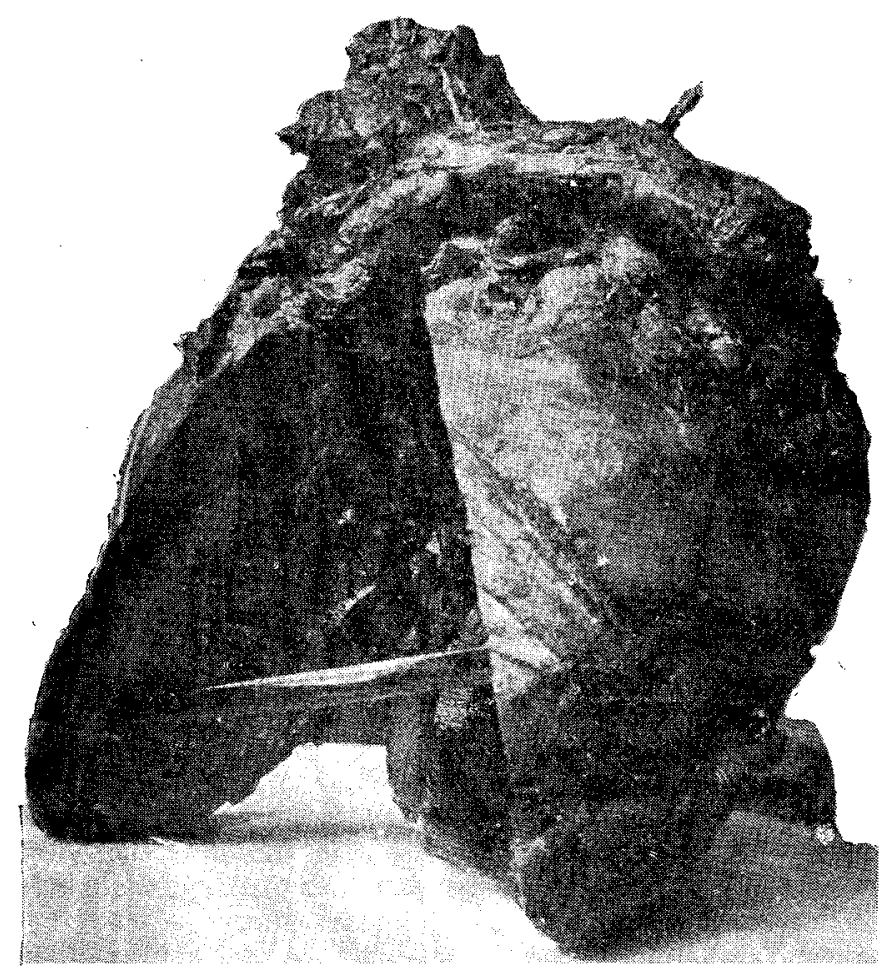

The cavities of the heart have been more widely opened. 'The enormously thickened caseating wall of the left ventricle is well seen, and the very small ventricular eavity.

normal. Both kidneys contained a few miliary tubercles, while large caseating areas were found in the mesenteric glands and miliary tubercles were scattered over the peritoneum. Many typical tubercular ulcers were found scattered throughout the small intestine. The brain was not examined.

So far, then, the necropsy notes show that the case was one of tuberculosis of the lnngs with a spreading general infection, the unique features being the extraordinary condition of the heart.

Description of the heart.-.. The heart was brought home from Fiji preserved in formalin and was opened and studied soon after its arrival at the London School of Tropical Medicine. The accompanying illustrations give some idea of the extraordinary lesions found in its walls after section and render a minute written description unnecessary. The left ventricle, perhaps more so than the other chambers of the heart, was greatly diminished in size owing to an enormous, more or less concentric, hypertrophy of the ventricular wall. The myocardium showed an extraordinary appearance, being infiltrated, or rather replaced, by caseous, cheesy masses of different sizes, these having produced the nodular or marblelike lumps seen on the outside of the heart during the necropsy. Fig. 1 shows these well. The wall at the base of the ventricle measured no less than $1 \frac{3}{4}$ in. in thickness, this gradually tapering to $\frac{3}{4}$ in. at the apex. Practically no normal muscular tissue was left, the tubercular lesions having entirely replaced this. Fig. 2 illustrates these points.

The right ventricle and both auricles were also affected, the cavity of the left auricle especially being surrounded and infiltrated by tubercular masses and thereby greatly obliterated. Remains of pericardium adherent and firmly bound to the auricles and great vessels at the base were easily found, but, as already mentioned, the pericardial membrane was, on the whole, quite free from tubercular changes.

The case furnishes an excellent example of a tubercular myocarditis, and with such advanced caseous masses replacing almost entirely the whole muscular substance of the heart it is extraordinary how life could have been prolonged as long as it was. The caseation and cheese-like masses were quite typical of tubercle, but to make absolutely certain of this sections were cut both of these and the lesions in other parts of the body. Histologically these showed typical tubercular lesions, and by Ziehl Neelsen's method tubercle bacilli were detected in large numbers in the material taken from the heart.

In conclusion, we must state how greatly indebted we are to Dr. Smartt for his kindness in allowing us to publish this case.

\section{Clinital Antes:}

MEDICAL, SURGICAL, OBSTETRICAL, AND THERAPEUTICAL.

"PANNICULITIS."

By Wirliay Batn, M.D. Durh., M.R.C.P. Lond.

FOR the past dozen years I have met patients who declined to continue massage on account of the pain it produced. This hyperæsthesia I thought then was purely neurotic. During the last few years I have had a number of these cases. On examination it was found that the hyperæsthesia was generally limited in extent and distributed in patches. The patches occur most frequently on the abdomen, next in order of frequency on the legs, arms, and back, and occasionally on the thorax. I will attempt to describe a patch. If you pick up the skin and subcutaneous tissue over it and roll them between the fingers they feel somewhat firmer and less elastic than the normal structures. The slight infiltration is either in the deepest layers of the corium, or in the subcutaneous tissue, or in both. Judging by tactile sensation $m y$ impression is that the inflammatory deposit is in the subcutaneous tissue. The sensitive areas are generally smooth, about 1 or 2 inches in diameter, and very tender on pressure. If the pressure is applied perpendicularly to the surface the tenderness is slight, but if applied from the circumference of the sensitive area it is very marked. A patch is evidently an aggregation of smaller ones. When the patch is disappearing under massage it splits up into several smaller ones, and the thickening therefore becomes uneven. The contour of the smaller patches can be made out, and before they finally disappear they feel like small pin-heads. These sensitive deposits occur chiefly in neurotic patients. Most of the patients are females about the middle period of life, and are inclined to be stout. I will briefly mention the last two cases I saw during the autumn.

Mrs. A, aged 46, gouty, had a bæmorrbage on the left side of the brain 12 years ago. The systolic blood pressure was 150 , and the weight 12 st. She was somewhat neurotic. She had a single patch in each upper arm; both were very painful when massaged.

Mrs. B, aged 48, had appendicitis four years ago; no operation on account of the feeble condition of her heart. The heart was slightly dilated and the pulse was weak. The systolic blood pressure was 99 , and the weight $14 \mathrm{st} .12 \mathrm{lb}$. The patient was not in the least neurotic. She had four patches on the abdomen which were very painful on pressure.

It is difficult to give an accurate description of the condition, as there is so little to feel. In the case of Mrs. B the exudations would probably have escaped observation were it not for the pain produced on examining the abdomen. 